\title{
STUDIESOF THE OTTOMANDOMAIN
}

\section{Garib-nâme’de Bazı Merhun Beyitlerde “Kim” Bağlama Edatlı Cümle İle “Çün” Cümle Başı Edatı Arasındaki İlgiler}

\section{The Interests of Compound Sentence with "Kim" and Attached Compound Sentence with} "Çün" in Consecutive Couplets of Garibnāme

\author{
Salih DEMIRBILEEK*
}

\section{Özet:}

$\mathrm{Bu}$ çalışmada Garibnāme'deki kimi ard arda gelen anlamca birbirine bağlı beyitler(merhun)'indeki kim'li birleşik cümle ile ona bağlı çün'lü birleşik cümleye dikkat çekilmiştir. Garibnāme için bu bir üslup özelliği olarak kabul edilebilir. Eski Anadolu Türkçesinin edebî dil olarak Farsçaya karşı hâkimiyet mücadelesini verdiği Beylikler döneminde kaleme alınan Garibnāme'deki bu tür yapılar eser ve dönemi için karakteristik bir görünüm sunmaktadır. Garibnāme'de kim'li ve çün'lü birleşik cümle yapıları sık kullanılmıştır. Bir beyitte tamamlanmayan anlamın devamındaki beyte aktarılma yollarından biri de cümle başı edatlardan yararlanmaktır. Özellikle çün ve genişlemiş biçimleri (çünküm / çünki, çün çün vs.) ile bu anlam geçişi, devamında gelen beyte kolaylıkla aktarılmaktadır.

Anahtar Sözcükler: Garibnāme, Âşık Paşa, Eski Anadolu Türkçesi, kim'li birleşik cümle, çün'lü birleşik cümle.

\begin{abstract}
:
In this study is pointed to some of compound sentence with "kim" and attached compound sentence which began with "çün" in consecutive couplets of Garibnāme. This can be considered as a stylistic feature of Garibnāme. It was written in the period of the Principalities which Old Anatolian Turkish struggle against Persian to dominate in literary language. Some of this kind of structures offers a new view for the work and its period. The structure of compound sentence with "kim" and attached compound sentence which began with "çün" is used frequently in Garibname. One of the way of transmission of meaning from one couplet to subsequent couplet is using of prepositional phrase. The meaning transition -from one to other- is transferred easily by means of prepositions, espacially "çün and extended formats of çün (çünküm/ çünki/ çün çün etc.).
\end{abstract}

Keywords: Garibname, Ashık Pasha, Old Anatolian Turkish, compound sentence with "kim", attached compound sentence with "çün".

\footnotetext{
* Yrd. Doç. Dr. Ondokuz Mayıs Üniversitesi, Fen-Edebiyat Fakültesi, Türk Dili ve Edebiyatı Bölümü
} 
Türk yazı dilinin ilk metinleri olan Köktürk yazıtlarının dili genellikle: "Kısa ve basit cümlelere" dayanır (Günşen 1995: 238). Eski Türkçenin Eski Uygur kolunda ise: "Çok yönlü, çok dinli, çok alfabeli Tarım bölgesinde" (Tekin 2001: 148) başlayan başta Sanskritçe, Toharca, Sakaca, Tibetçe gibi çevre dillerinde özellikle dinî metinlerin çevirisiyle -edatlar da dâhil olmak üzere- dile yabancı terimlerin girmesi hızlanır. Orta Türkçe döneminin yazı dillerinin tamamında yabancı unsurlar Eski Türkçedeki gibi dini terminolojiyle sınırlı kalmaz aynı zamanda avam söz varlığı da dile yoğun girer ki bu dâhil olmanın pek çoğu da keyfîdir. Benzer bir durum Eski Anadolu Türkçesi (=EAT)'nin kuruluşunda Anadolu'da yaşanmıştır. EAT'nin ilk metinlerinde yer alan Oğuz-Kıpçak ağız unsurlarının yan yana bulunduğu karışık dilli eserlerin içerisinde hatırı sayılır Farsça ve Arapça leksik ve gramatikal unsur bulunur. Özellikle tercüme ve divan şiiri bu unsurları gitgide yoğunlaştırır.

EAT metinlerinin önemli bir kısmı tercümedir. Yapılan çeviri birlikte kaynak diller olan Farsça ve Arapça kimi dil öğeleri de Türkçeye tıpatıp kopya ediliyordu. Özellikle Türkçenin sentaksına aykırı tamlamalar, devrik ki'li cümleler /bağlı kim'li cümleler, çü/çün /çünki/çünküm/ çün çün vs. türevleriyle bir kısım edatlar sade nesir ile yazılmış eserlerde dahi sıkça yer almaktaydı.

EAT dönemi metinlerinden Garibnāme'de de kim'li ve çün'lü cümle yapılarına sıkça rastlanılmaktadır. Kim edatı çeşitli görevlerde eserde yaygın olarak kullanılmıştır. Ancak bu çalışmada kim edatının sadece birleşik cümle olarak görev yaptı̆ğ kullanımlar dikkate alınmıştır. Garibnāme'de kim edatı gramatikal yapı olarak birleşik cümle oluştururken çün bağlama edatı anlam açıcı bir leksik öge durumunda metinde yer almıştır. Çalışmanın amaçlarından biri de Garibnâme'den hareketle EAT’nin söz dizimi hususiyetlerine dikkat çekmektir.

Türkçe kim'li birleşik cümle ile Farsça "sebeb bildiren" (Timurtaş 1985: 312) çün'lü birleşik cümle yapıları Orta Türkçe metinlerinin karakteristik bir hususiyeti olarak özellikle çeviri eserlerde sık görülürler. "Türkçede aslında bağlama edatı yoktu. Bağlama edatları Türkçede sonradan ve yabancı dillerin tesiri ile ortaya çıkmıştır. Onun için Türkçede kullanılan bağlama edatlarının büyük bir kısmı yabancı asıllıdır. Türkçede olanlar da bazı isim ve fiil şekillerinin sonradan edatlaşması ile ortaya çıkmıştır” (Ergin 1985: 352).

Kimli birleşik cümleler Eski Uygurcadan başlayarak dilde çeşitli görevlerde bulunmuşlardır (Özkan 2004: 243-255; Savran 2004: 319-336). Orta Türkçe metinlerinden başlayarak dilde Türkçe kim'li birleşik cümle ile Farsça ki'li birleşik cümle yapıları yan yana kileyin birbirinin yerine karış1k olarak aynı metinde kullanılmışlardır. Bazı eserlerde ki'li birleşik cümlenye oranla kim'li birleşik cümle daha çok kullanılmıştır. Dedem Korkut Kitabında 30 ki'li cümleye karşılık 74 kim'li cümle vardır (Ergin 2009: 482). Ancak daha sonra dilde bu kullanım sıklığ 1 hatta tercihi ki'li birleşik cümle lehine dönmüştür. "Batı Türkçesinin Eski Anadolu ve Osmanlıca devrelerinde Farsça ki ile yan yana yaşayan kim, Türkiye Türkçesinde artık tamamen kaybolmuştur” (Hacıeminoğlu 1984: 172).

Ki edatı gibi Farsçadan alınma Çün bağlama edatı ise: "çünki, zira, madem ki, ne zaman ki vb." anlamları ile "Harezm, Çă̆atay, Kıpçak ve Anadolu metinlerinde çok kullanılmış bir cümle başı edatıdır" (Hacıeminoğlu 1984: 133). Akalın, çün'ün anlamlarını şu şekilde sıralamaktadır: "Eğer,

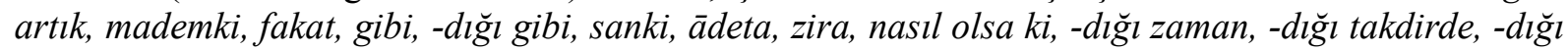
için, -dıktan sonra" (Akalın 2007: 59). "Eski Anadolu Türkçesi döneminde Arapça ve Farsçadan dilimize tercüme edilen eserler vasitasıyla Türkçenin cümle yapısına giren bu özellikler, daha sonraki dönemlerde fonksiyonlarını kaybederek Türkçe zarf-fiil ekleriyle karşılanmışlardır. Hatta bu dönem eserlerinde bile bazı örneklerde bu cümle başı edatları fonksiyonlarını yitirerek cümlede zarf-fiil ekleriyle beraber yer almaktadır" (Yavuzarslan 2002: 78-79). Garibnâmede ki/kim edatının birleşik yapılı varyantları olan çünkim, nitekim, niçekim, sankim, şol kim, belkim ile çün'ün varyantları çü çünan, imdi çün, çün çün de kullanılmıştır. 
1. G. (=Garibnâme $)^{1}$ nin kimi beyitlerinde her iki dizede de bir basit cümle yer alır. Kim bağlama edatı ile bu basit cümleler, bağlı birleşik cümle biçimine sokulur. Kim bağlama edatı da çün edatı gibi dize başında yer almaktadır. Akabinde gelen beyitteki çün'lü cümle ise anlam açıcı olarak önceki beyitle/cümlelerle ilişkilendirilir:

Altı dürlü iş gerek yol ehline

Kim ol işler direk ola bu dine 3621, I/2

Çün ola bu altı iş kāyim dürüst

Yol eri yolda ola çālāk ü çüst 3622, I/2

....

Anı anuñçun buyurdı ol Ahad

Kim bize rehber ola ol tā-ebed 8322, II/2

Çün Habib'e Hak'dın emr oldı bu iş

Eytdi kılgıl günde biş kez yaz u kış 8323, II/2

...

Diñle imdi bu hikāyet vasfinı

Kim bilesin sen bu sözüñ aslını 3938, I/2

Çün yaratdı 'ālemi ol pādişāh

Gör ki ne kildl vü n'itdi ol ilāh 3938, I/2

....

2. G.nin kimi beyitlerinde ilk dize bir basit cümle; buna karş1lık ikinci dize (devrik) kim'li birleşik cümle biçimindedir. Kim bağlama edatı dize ortasında kullanılmıştır. Türkçe kim bağlama edatı metinlerde Farsça ki edatının görevini de üstlenerek devrik cümleler de kurmuştur. Türkiye Türkçesinde kim edatının yerine yazı dilinde ki kullanıldığı için ki edatı hem devrik cümle hem de bağlı cümle kurmaktadır:

Ol 'ademde kamust penhān-idi

Sanasin kim togmaduk oglan-idi 1243, I/1

Çün işāret kıldı Hak bir kez aña

Cümlesi oldı tamām öñden soña 1243, I/1

....

Kankı bayda kim sehāvet olmadı

Şöyle bil kim ol cihāna gelmedi 9088, II/2

Çün sahidür bayllg oldur kirtü bay

Nitekim olmışdı ol Hātim-i Tāy 9089, II/2

3. G.nin kimi beyitlerinde ikinci dizede yer alan kim'li cümle, ilk dizedeki birleşik cümlenin temel cümlesine bağlanmaktadır:

İşid imdi ne'ydügin eydem saña

Kim bilesin bu işi öñden soña 5664, II/1

Çün kim Allah dünyaya virdi vücūd

\footnotetext{
${ }^{1}$ Örnekler için Kemal Yavuz neşri kullanılmıştır. İlk rakam beyit numarası; italik rakam ise cilt numarasını göstermektedir.
} 
Kim aniñdur bahşiş ü ihsān u cūd 5665, II/1

Niçe eydem hālümi kim ne olmışam

Eyle san kim varligumdan olmışam 7976, II/1

Çün temāmet varligum gitdi benüm

Yine geldi ‘ş̧k elüm dutdı benüm 7977, II/1

İşid imdi niçedür eydem 'āyān

Kim bilesin bu işi bellü beyān 3233, I/2

Çün çalap dergāhina yol buldı cān

Cān içinde kalmadı hergiz gümān 3234, I/2

4. G.nin kimi beyitlerinde kim bağlama edatı, ikinci dizenin ortasında kullanılmıştır. İlk dizedeki cümle/ler bağımsız bir yapıdadır. İkinci dize (devrik) kimli birleşik cümle biçimindedir. Çün sadece ikinci dizenin açıklayanı durumundadır:

Ulu hil'atdur bu dervişlik ere

Kāni' olursa suña kim Hak vire 9101, II/2

Çün kanā'at dervişe hemrāh ola

Gözde dervīş ü gönülde şāh ola 9102 , II/2

$\ldots$

Bì-hod olur pes düşer ol dem yire

Ya'ni ma'şūkçun diler kim cān vire 6473, II/1

Çün görür bu hāl--lla gül bülbüli

Bülbüle söyler bu kez ol gül dili 6474, II/1

Göz gerek kim göre vü 'akl añlaya

Añlayanlar lācerem kim tañlaya 6744, II/1

Çün açıldı 'Aşılk'a bu medrese

Gözine 'ibret görindi her nese 6745, II/1

Her kim ol işde degüldür er degül

Yoga saygıl sen anı kim var degül 8642, II/2

Çün bakarsañ kamu nesne işdedür

İlla işi her birinün gör nedür 8643, II/2

5. G.nin kimi beyitlerinin ilk dizesi basit cümlelerden oluşmuş sıralı cümle topluluğu halinde iken ikinci dize kim'li birleşik cümle biçimindedir:

Pādişāh gördi begendi old s şād

Diledi kim çıkara dünyada ad 1529, I/ 1

Çün gözine hoş görindi ol ara

Pes buyurd yapdılar köşk ü serā 1530, I / 1 
Gör ki sen kimsin bu yir ü gök nedür

Diñle imdi kim hikāyet nitedür 4574, I/2

Çün yaratdl yiri gögi ol Kadìm

Gör ne hikmet birle düzdi ol Hakìm 4575, I/2

\section{Sonuç:}

Bu çalışmada Garibnāme'deki kim'li birleşik cümle ile onu takip eden çün'lü cümle ele alındı. EAT metinlerinde sık geçen bu iki cümle türü arasındaki leksik ve gramatikal ilişkiler, dönemin diğer eserlerdeki örneklerle şüphesiz daha ayrıntılı olarak çeşitlendirilebilir. Böylece bu dönemin sentaks hususiyetleri sağlam kaidelere bağlanabilir.

Kim'li birleşik cümlelerin yer aldığı beyitlerle akabinde çün cümle başı edatı ile gelen beyitler incelenmiştir. Kim bağlama edatı kimi durumlarda beytin her iki dizesindeki iki ayrı basit cümleyi birbirine bağlarken kimi durumlarda ilk dize bağımsız bir cümle ya da cümleler topluluğu olmasına karşın; ikinci dizedeki cümleleri yönetmektedir. Çün bağlama edatı ise anlam açıcı rolünü üstlenerek üst beyitle anlamsal ilişkilendirilmektedir. Böylece anlamın daha geniş bir yayılma alanı bulduğu paragraf / metin(text) bölümleri ortaya çıkmaktadır. Çün'lü cümle bu haliyle metindilbilimsel anlamda bir tutarlılık öğesi konumundadır. Kim bağlama edatı cümlede gramatikal (görevsel); çün bağlama edatı ise leksik (anlamsal) işlevde kullanılmaktadır.

EAT metinlerinin ses ve biçim yapısı üzerinde pek çok çalışma yapıldığı halde bu dönemin sentaksı yeterince işlenmemiştir. Özellikle bu dönemde kullanılan edatların geçtiği metin bağlamında birbirleriyle ilişkilerini irdeleyen çalışmalar hemen hemen hiç yapılmamıştır. Dolayısıyla bu dönemin sağlam bir grameri için ses-biçim konularından ziyade sentaks konulu monografiler/tezler yapılmak suretiyle dönemin sentaks hususiyetleri ortaya çıkarılmalıdır.

\section{Kaynakça:}

Akalın, Şükrü Haluk (2007), "Eski Anadolu Türkçesinde Çün, Çünki, Çünkim Cümle Başı Edatlarıyla Kurulmuş İsim Cümleleri”, IV. Uluslar arası Türk Dili Kurultayı Bildirileri - I (24-29 Eylül 2000), Ankara: Türk Dil Kurumu Yayınları, s. 57-65.

Cemiloğlu, İsmet (1994), 14. Yüzyıla Ait Bir Kısas-ı Enbiyā Nüshası Üzerinde Sentaks İncelemesi, Ankara: Türk Dil Kurumu Yayınları, s. 60-63.

(2001), Dede Korkut Hikāyeleri Üzerinde Söz Dizimi Bakımından Bir İnceleme, , Ankara: Türk Dil Kurumu Yayınları, s.80

Ergin, Muharrem (1985), Türk Dil Bilgisi, 15. Baskı, Boğaziçi Yayınları: İstanbul. (2009), Dede Korkut Kitabı -2 İndeks-Gramer, 4. Bask1, Ankara: Türk Dil Kurumu Yayınları.

Günay, V. Doğan (2003), Metin Bilgisi, 2.Bask1, İstanbul: Multilıngual Yayınları.

Günşen, Ahmet (1995), “Eski Türkçe (Köktürkçe)'nin Cümle Yapısı ve Tahlili”, Tuncer Gülensoy Armağanı, Yayına Hazırlayan: Ahmet Buran, Kayseri: Bizim Gençlik Yayınları: s.

229- 241. 
Hacıeminoğlu, M. Necmettin (1984), Türk Dilinde Edatlar (En Eski Metinlerden Zamanımıza Kadar) -Yazı Dilinde-, Üçüncü Basılış, İstanbul: Milli Eğitim Bakanlığı yayınları: İstanbul.

Özkan, Mustafa (2004), "Eski Türkiye Türkçesinde ki / kim Bağlaçlarının Kullanılışı Üzerine”, Türk Dili ve Edebiyatı Dergisi, İstanbul: İstanbul Üniversitesi Edebiyat Fakültesi Yayınları, s. 243-255,

Savran, Hülya (2004), "Uygurca ve Orta Türkçe Dönemindeki 'Kim'li Birleşik Cümlelerde Şartlı Yardımcı Cümleler ve Bu Cümlelerin Ana Cümleye Katılma Şekilleri”, Türk Dili ve Edebiyatı Dergisi, İstanbul: İstanbul Üniversitesi Edebiyat Fakültesi Yayınları, s. 243-255,

Tekin, Şinasi (2001), "Eski Türk Yazı Dillerinin Özellikleri üzerine Düşünceler ve Bunların Teşekkülü ile Türk Siyasi Birlikleri Arasındaki İlişkiler”, İştikakçının Köşesi Türk Dilinde Kelimelerin ve Eklerin Hayatı Üzerine Denemeler, İstanbul: Simurg yayınları, s.121-149.

Timurtaş, Faruk K. (1985), Osmanlı Türkçesi Grameri III (Eski Yazı ve imlā-Arapça-Farsça-Eski Anadolu Türkçesi), 5.Bask1, İstanbul Üniversitesi yayınları: İstanbul.

Yavuz, Kemal (2000), Aşık Paşa, Garib-nāme (Tıpkıbasım, karşılaştırmalı metin ve aktarma), c. I-I/II, II-I / II, Ankara: Türk Dil Kurumu Yayınları..

Yavuzarslan, Paşa (2002), Mūsā bin Hācı Hüseyin el-İzniki, Münebbihü'r-Rākidin (Uyurları Uyandurucu) Giriş-İnceleme-Tenkitli Metin, Ankara: Türk Dil Kurumu yayınları.

Yazım Kılavuzu (2005), Ankara: Türk Dil Kurumu Yayınları.

Yelten, Muhammet (1993), Şirvanlı Mahmud Kemāliyye (Giriş-İnceleme-Cümle Bilgisi-MetinSözlük), s. 43-55, İstanbul: İstanbul Üniversitesi Yayınları. 